\title{
Development of Foreign Language Teachers' Diagnostic Competence in the System of Military Education
}

\author{
Vasyl Yahupov ${ }^{1}$, Olha Zastelo ${ }^{2}$, Valentyna Svystun ${ }^{1}$, \\ Nataliia Korchynska ${ }^{2}$, Olena Chorna ${ }^{2}$, Viktoriia Krykun ${ }^{1}$ \\ ${ }^{I}$ National Defense University of Ukraine named after Ivan Cherniakhovskyi, \\ 28 Povitroflotsky Avn., Kyiv, Ukraine \\ ${ }^{2}$ Academy of the Foreign Intelligence of Ukraine, 11 Bulvarno-Kudriavska St., Kyiv, Ukraine
}

\begin{abstract}
The article is dedicated to the problem of foreign language teachers' diagnostic competence development. It reveals the problematic issues connected with the obtaining integral estimates of students' foreign language communicative competence formation levels. The study presents a technology of integrated assessment based on the recent mathematical and statistical methods realized with the help of information and communication technologies. The first experiment proves the technology contributes to the accuracy and reliability of integral estimates by $9,1 \%$. The second one assures that training teachers to use the technology improves their levels of diagnostic competence by $21,9 \%$ in average.
\end{abstract}

Keywords - teachers' diagnostic competence, integral estimate, mathematical and statistical methods, integrated assessment technology, artificial neural network.

\section{Introduction}

In the context of gradual Euro integration of Ukraine, its political, economic, social and defense

DOI: $10.18421 /$ TEM93-49

https://doi.org/10.18421/TEM93-49

Corresponding author: Olha Zastelo,

Academy of the Foreign Intelligence of Ukraine, 11

Avenue - Kudriavskaya St., Kyiv, Ukraine.

Email: zolga777@ukr.net

Received: 31 March 2020.

Revised: 17 June 2020.

Accepted: 21 July 2020.

Published: 28 August 2020.

(c) BY-NC-ND@ 2020 Olha Zastelo et al; published by UIKTEN. This work is licensed under the Creative Commons Attribution-NonCommercial-NoDerivs 4.0 License.

The article is published with Open Access at www.temjournal.com sectors as well as the higher military education system are being modernized.

Its modernization is caused primarily by the state's defense tasks and the importance of the quality assurance of the officers' military and professional training. In this aspect, the system of the officers' foreign language training plays an extremely important role because their foreign language communicative competence (FLCC) formation/development levels influence the quality of vocational tasks solving, especially during the international and other military and professional activities. The formation of the officers' FLCC as students in the system of the military education significantly depends on the way the Foreign Languages discipline is being taught to them.

The pedagogical diagnostics is a special pedagogical method used both for discovering and measuring the success of students' learning and for the outlining the ways with regard to achieving the hierarchy of pedagogical goals while teaching. Thus, the objectivity of the students' FLCC estimates depends on how adequately foreign language teachers (hereinafter - the teachers) do the assessments according to the real status of this professionally important students' competence. For this purpose, the teachers' diagnostic competence should become a subject of constant development as an essential part of their professional and pedagogical competence.

\section{Theoretical Bases of the Study}

The problem of the teachers' professional competence development and its components is covered in the works by Y. Bandura, Y. Baumert [1], G. Jones, I. Ziazun, M. Kunter [1], L. Horuzhaya and others. A number of foreign and Ukrainian scientists such as C. von Aufschneiter [2], S. Bruder [3], O. Chernikova [4], P. Edelenbos [5], G. Gats, N. McElvany[6], J. Klug[3], S. Martynenko, A. Ohle[6], E. Wuttke[7] and others distinguished 
diagnostics among the components of teachers' professional competence.

In particular, German scientists Ch. Bruehwiler et al. consider, that "diagnostic competence is one of the main competencies that a teacher should have to be able to deal with the current and future challenges of teaching at a school" [8]. The diagnostic competence is viewed as a precondition for adaptive teaching competency, which is defined as "the teacher's ability to adjust instruction to the individual learning processes of pupils in such a way as to create favourable conditions for each student's learning for understanding" [9].

The paper by A. Ohle and N. McElvany addresses diagnostic competence as part of teachers' expertise and focuses on aspects of diagnostic competences as prerequisites for accurate diagnostic judgments. The authors outline the following competency facets: attitudes towards diagnostics, motivation towards diagnostics, self-efficacy beliefs, and self-reflection in diagnostics. It is worth mentioning that "the teachers should be able to meet these complex and diverse requirements in their daily work, they should be trained in professional diagnostic competences in their university and postgraduate studies" [6].

According to Polish researcher B. Niemierko, the diagnostic competence of the teacher includes the ability to pick the necessary diagnostic tools, which are appropriate to the situation; to be able to didactically reasonably use them; to interpret the obtained diagnostic results; to use the results of diagnosis in their activities; to present the results of diagnosis to students and their parents, as well as to the management and other teachers [10].

To meet the outlined need for measures in order to enhance teachers' diagnostic competence, M. Trittel et al. conducted a study in order to develop and evaluate a training program in educational diagnostics for prospective teachers with a specific focus on the development of practical competences that are actually relevant to teachers' future professional work [11].

J. Klug defines the teachers' diagnostic competence as the "ability to interpret students' academic growth and their growth in using learning strategies" [3]. J. Klug et al. developed and empirically tested a model of teachers' diagnostic competence that represents the process of diagnosing learning behavior. It describes the diagnosis of learning behavior as a three-dimensional process or model that consists of a pre-actional, actional, and post-actional phases [12]. The author advises to teacher educators and those involved in the professional development of teachers to use the model's theoretical framework, focusing their training courses on the model components and process character. Various tasks (case scenarios, discussion with fellow students, who can benefit from each other, and the feedback given by teacher educators) can be used in teacher education to promote teachers' diagnostic competence. In addition to the training content, the diary can help teachers reflect upon their diagnostic action and be a source of motivation. Diagnostic competence can be used for designing classroom environments to meet the needs of students and in adapting activities that can make learning more effective according to students' needs [12].

In this way, the analysis of modern Ukrainian and foreign pedagogical theory and practice on the problem reveals that teachers' diagnostic competence is considered to be a result of teachers' professional development, but there has been little research on factors, which influence teachers' diagnostic competences and can be modified during teachers' trainings. On the one hand, the teachers should pay more attention to the constant development of their diagnostic competence, search for possibilities of its promotion in order to be up to the challenges of the modern education systems. On the other hand, there are not enough tools for developing the teachers' diagnostic competence that makes the problem of the article topical and urgent.

\section{Development}

The purpose of the article is to justify the methodological basis for the development of the foreign language teachers' diagnostic competence in the higher military education system using the technology of integrated assessment of students' FLCC formation levels realized by means of recent mathematical and statistical methods and information and communication technologies (ICT).

The results of the analysis of scientific sources and pedagogical practice show that the diagnostic activity is a system-building component in the structure of teachers' pedagogical one, since it provides data communication between the purpose and the result, and enables the creative organization of teachers' diagnostic activity with the help of recent ICT and to correct and improve it in time. The teachers' diagnostic activity is a complex of various pedagogical preparatory, methodical, monitoring, evaluation and other procedures, methodical actions, measures and justifications for the assessment of students' FLCC formation levels. In order to act properly, teachers have to possess well-developed diagnostic competence as an integral and compulsory component of their professional competence, as well as constantly develop this competence in accordance with the requirements of educational assessment in the information society [13]. 
In this way, we define teacher's diagnostic competence as their intellectual, agent-activity ability, professional, personal and psychological readiness for realization of diagnostic function by creative adherence to the pedagogical principles of diagnostics and usage of recent diagnostic techniques, methodologies, technologies while performing this pedagogical function [14].

According to the principles of systematic, contextual, competence and agent-activity methodological approaches, we distinguish such components of teacher's diagnostic competence as value-motivational, cognitive, operational-activity and reflexive-corrective ones. These components encompass teacher's diagnostic activities consistently, comprehensively, systematically and contextually.

With the objective to diagnose the teachers' diagnostic competence development levels correctly, it is necessary to have certain systemic, contextual and reliable performance criteria that are deliberately designed for this purpose. Taking into consideration the requirements of the contextual approach (i.e. teaching a foreign language to the military officers), the skills-oriented approach (i.e. basic components of diagnostic competence) and the agent-activityoriented one (i.e. diagnosed by the teacher as agent of pedagogical activity), we distinguish the following compulsory criteria:

- a value-motivational criterion, which means that teachers have positive attitude to diagnostic activity in general and data obtained during the diagnosis process with the help of mathematical and statistical methods of processing, they focus on systematic and contextual application of ICT during the diagnostic activity;

- a contextual and institutional criterion, which implies that teachers have systemic and contextual knowledge in the professional subject, in the methods and means of diagnostic activities, in recent mathematical and statistical methods of diagnostic data processing, in advanced ICT, and in the way how all the mentioned above can be implemented;

- a praxeological criterion, which stipulates that teachers have ability to organize their diagnostic activity and realize their diagnostic function, to select mathematical and statistical methods of diagnostic data processing using ICT in accordance with the of diagnostic tasks;

- a result-corrective criterion, which specifies that teachers are able to evaluate the effectiveness of mathematical and statistical methods of diagnostic data processing using ICT, to analyze the results of diagnostics, to choose their own behavioural strategies of diagnostic activity; to self-educate and impartially evaluate their capabilities and results of diagnostic activity.
We define three levels of teachers' diagnostic competence development: basic (knowledge and reproductive), professional and functional (theoretical and orientational), creative and professional (analytical and productive) [14].

In order to obtain integrated estimates of the students' FLCC formation levels, teachers use tests of different types and forms of implementation, depending on what FLCC components are important regarding students' military and professional activities, and then they need to do correct mathematical and statistical processing of the test outcomes. As the result we obtain an integral estimate of the student's FLCC formation level, i. e. an aggregate characteristic indicator that is formed on the basis of functional dependence on its partial components, and adjusted according to their weight in the structure of the FLCC.

Having comprehensively analyzed the pedagogical assessment practice in the military education system, we determined that the assessment is carried out predominantly at the intuitive and logical level with the help of such methods of pedagogical diagnostics as tests and the test outcomes are processed according to an arithmetic weighted convolution. In addition, it was proved that the choice of different mathematical and statistical methods of test data processing leads to divergency in the integrated estimates of students' FLCC formation levels. In particular, we found out that the integrated assessment accuracy and reliability depend greatly on the following factors: scale type to measure test outcomes, type of convolution, method of expert evaluation, ranking method, method of determining the objectivity of each expert, and degree of the expert panel opinion consistency [14], [15].

In this regard, our task was to find and justify the ways to eliminate the dependence of the integrated estimates of students' FLCC formation levels on the methods chosen by the teachers, and to process the tests outcomes. In other words, it is necessary to choose among the recent mathematical and statistical methods and their variants those, which would be invariant, i.e. they would not depend on the type of convolution and the scale to measure the tests' outcomes, but would provide the accuracy and reliability of assessment and would be appropriate for the pedagogical diagnostic task.

For this purpose, we elaborated and substantiated the integrated assessment technology of the students' FLCC formation levels. This technology encompasses the aim, techniques, methods, means and forms of the assessment, which ensures the successful achievement of advance recognition goals with the help of ICT in combination with the regulatory, technical, organizational and methodological support for its application (Fig. 1). 


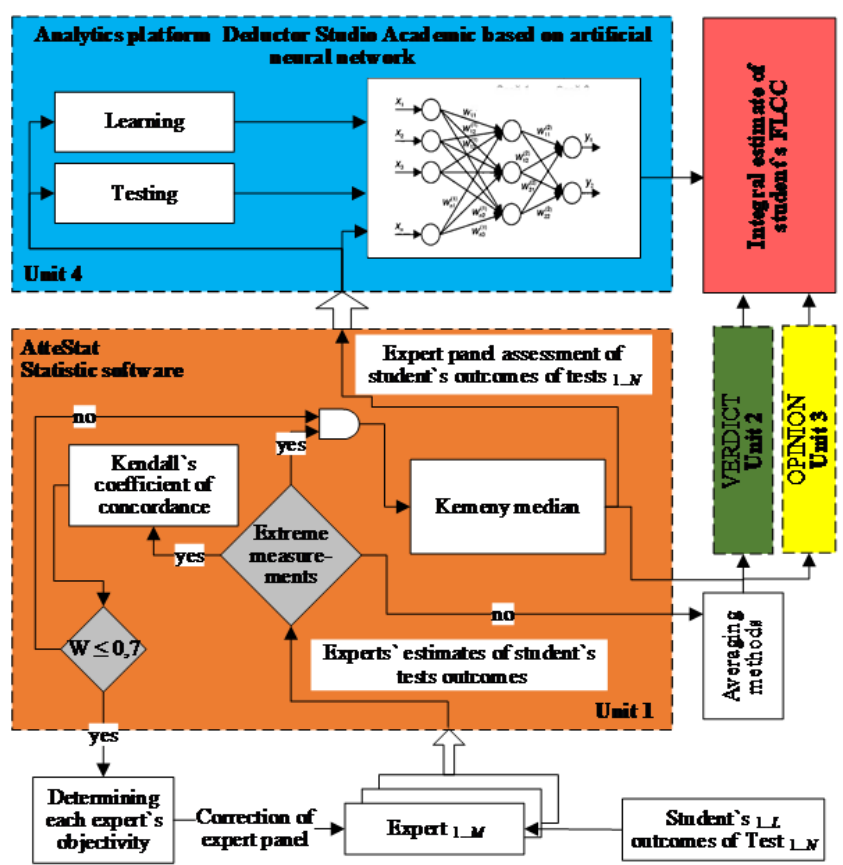

Figure 1. Schematic Structure of the Integrated Assessment Technology

Unit 1 provides the students' tests outcomes processing based on the expert panel evaluation. There can be used the method of ranking and data processing according to the Kemeny median, the coefficient of concordance (consistency of the expert panel) and determining each expert's objectivity with the help of AtteStat statistical software.

Unit 2 allows the selection of a measurement scale and implementation of an integral aggregation convolution that integrates several tests outcomes processed with the help of VERDICT statistical software.

Unit 3 enables iterative procedures to ensure the consistency between different expert evaluation methods, when the data processing outcome by one method can be used as an input for the other methods. Due to this, the statistical error of each method is reduced. These procedures can be performed with the help of OPINION statistical software.

Unit 4 involves the application of an artificial neural network to improve the data processing during expert evaluation of students' tests outcomes and to determine the integral estimates of students' FLCC formation levels taking into account the test weighting. The principles of nonlinear generalization that underpin the artificial neural network provide further effective use of the experts' accumulated diagnostic experience. This is performed with the help of Deductor Studio Academic analytics platform.

The expert panel evaluation data processed with the help of the mentioned above software in order to testify the validity of the assumptions about the influence of the measurement scale, the integral convolution and the procedure of integrating the methods of expert information handling in order to get the integrated estimates of the students' FLCC formation levels. A positive achievement is successful application of artificial neural network technology capabilities to adaptively create an algorithmic convolution while "transferring" expert's experience into the memory of the artificial neural network model, which simulates the examiner's assessing activities while determining the students' FLCC formation levels.

VERDICT statistical software performs a unified approach to the construction of the object quality model based on the multidimensional analysis. VERDICT performs statistical analysis of data in the following main areas: evaluating and ordering objects' characteristics based on the indicators of the most known methods of selection (convolution calculation) and the original algorithm for solving the convolution selection problem; objects' classifying according to such indicators as determining the number of partitioning classes and selecting groups of similar objects.

OPINION statistical software implements mathematical and statistical expert evaluation methods to formalize experts' opinions about the object under study. OPINION performs statistical processing in such main areas as: elaboration of experts' opinions on the basis of the available selection methods (convolution determination) and the original algorithm of complex use of expert evaluation methods; analysis of consistency of expert estimates based on statistical characteristics (concordance), association coefficients and rank correlation.

The choice of VERDICT and OPINION software was made due to some factors. The programs are specialized by author's developments to solve similar tasks. They are freely distributed for educational and scientific institutions. It is possible to engage the developers to support these programs for installation, setup, training, further expansion of capabilities and so on.

AtteStat software [16] is designed for the professional statistical processing of data in various fields. This software applies different methods of expert evaluation processing, namely: evaluation methods (the pairwise comparison method, the group estimation method); methods of assessing the consistency of experts' opinions (Kendall's coefficient of concordance, Cronbach's alpha); methods of obtaining experts' collective opinion (the mid-rank method, the Kemeny median, the Kemeny mean).

These methods represent different statistical approaches to solve the problems of the same type, 
and they can perform the same results under certain conditions. Moreover, to resolve the defined problems we need to implement complex information and analytics technologies applicable in the education field. One of such recent software is Deductor Studio Academic [17]. This analytics platform enables us to create complete applied solutions and to do data analysis. Every stage of an analytical system construction from data consolidation to model construction and obtained results visualization can be performed due to its technologies based on unified architecture.

This program can be used for data analysis, and for process and forecasting model creation. To operate the system, the following operations should be fulfilled: collecting statistics about the process under study, "teaching" the neural network on the given data and checking the results. While "learning" the artificial neural network selects the weights independently and builds the model that most accurately reflects the process under study.

\section{Results and Discussion}

In the modern information society, the teacher has to know about ICT innovations and how to apply them in their pedagogical activities, i.e. how to apply the variety of the recent methods, techniques, ICT and some tools for the diagnostic function [13], [18]. Before applying the technology of integrated assessment of students' FLCC formation levels as a methodological background for teachers' diagnostic competence development, it was necessary to experimentally verify its reliability and effectiveness. The survey was conducted in groups of 390 students in $2015-2017$ years. Initially, the students did a set of tests and the examiners graded students' tests outcomes. Then the calculating of the integral estimates of students' FLCC formation levels was performed in three ways. Firstly, the benchmark integral estimates were calculated as a result of expert evaluation of students' tests outcomes by some experienced examiners. Secondly, the traditional method was used, which implied calculating integral estimates with the help of the arithmetic mean of the graded students' tests outcomes. Thirdly, the same graded students' tests outcomes were processed with the help of the technology to obtain the integral estimates of students' FLCC formation levels.

The comparative analysis of the data on the distribution of integral estimates of students' FLCC formation levels, which were calculated according to the traditional method and the technology (Table 1), has revealed the following differences:

- the elementary level of FLCC formation was detected in 47 students (24\%) (difference of 8 persons or $4 \%$ with the benchmark result of 39 persons or $20 \%$ ) and 31 students or $16 \%$ (difference of 8 persons or $4 \%$ with benchmark result of 39 persons or 20\%) accordingly;

- the intermediate level of FLCC formation was found in 82 students (42\%) (difference of 6 persons or $3 \%$ with the benchmark result of 88 persons or $45 \%$ ) and 86 students (44\%) (difference of 2 persons or $1 \%$ with the benchmark result of 88 persons 45\%) accordingly;

- the advanced level of FLCC formation was detected in 66 students (34\%) (difference of 2 persons or $1 \%$ with the benchmark result of 68 persons $35 \%$ ) and 78 students (40\%) (difference of 10 persons or $5 \%$ with the benchmark result of 68 persons $35 \%$ ) accordingly.

Table 1. Distribution of Integral Estimates of Students' FLCC Formation Levels

\begin{tabular}{|c|c|c|c|c|c|c|c|}
\hline \multirow[t]{2}{*}{ 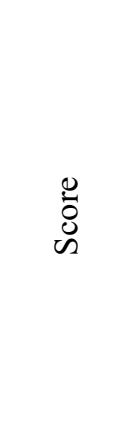 } & \multirow{2}{*}{ 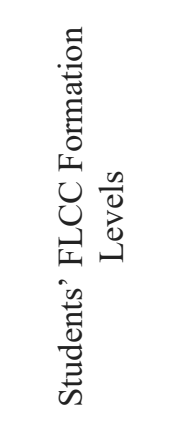 } & \multicolumn{2}{|c|}{ 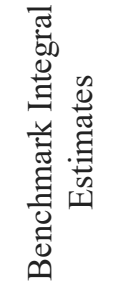 } & \multicolumn{2}{|c|}{ 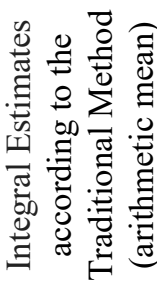 } & \multicolumn{2}{|c|}{ 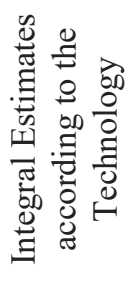 } \\
\hline & & 己ٍ & $\%$ & 节 & $\%$ & 苂 & $\%$ \\
\hline $1-59$ & elementary & 39 & 20 & 47 & 24 & 31 & 16 \\
\hline $60-79$ & intermediate & 88 & 45 & 82 & 42 & 86 & 44 \\
\hline $80-100$ & advanced & 68 & 35 & 66 & 34 & 78 & 40 \\
\hline
\end{tabular}

The statistical analysis of these controversial tests' outcomes and the calculation of integral estimates of students' FLCC formation levels were performed with the help of STADIA statistical software [19]. The error of the integral estimates calculation is $9,1 \%$ less compared to the benchmark ones, when the processing was done according to the technology. Therefore, this technology is proved to be effective and it contributes to more objective results of diagnosing the integral estimates of students' FLCC formation levels. That is why we recommend using it as a methodological background and a tool to develop teachers' diagnostic competence.

With the purpose of successful implementation of this technology into pedagogical practice, namely to teach the teachers how to use it, we compiled methodological recommendations [20] and introduced an educational course within the framework of corporate training, which was conducted in three stages: information and 
enrichment stage, instrumental and reproductive stage and activity-adaptive one. The recommendations represent methodological support for the course and while compiling them we took into account not only the teachers' specific professional activity, but also the peculiarities of their diagnostic competence development. The teachers are expected to take the following steps in order to develop their diagnostic competence: to read "Methodical Recommendations for Teachers on the Application of the Integrated Assessment Technology" [20], to watch the video course that demonstrates the diagnostic actions of a teacher, to get advice from other colleagues if necessary, to participate in training, to work independently and to implement their methodological achievements in diagnostic practice. The aim of teacher' training is to obtain more accurate integral estimates of students' FLCC formation levels as a result of successful realization of their well-developed diagnostic competence.

Consequently, these theoretical, methodological and practical achievements became the subject of the pedagogical experiment. At the final stage, it was necessary to verify that the technology of integral assessment of students' FLCC formation levels can be successfully used as a methodological background for teachers' diagnostic competence development. 126 foreign language teachers from higher military education institutions participated in this experiment. At the beginning of the pedagogical experiment, there was no statistically significant difference in the teachers' diagnostic competence levels either in the control group (CG) of 62 persons or the experimental group (EG) of 64 persons, so the groups were considered homogeneous. The CG teachers tried to master the technology by themselves or did not do anything to develop their diagnostic knowledge and skills. The EG teachers took the mentioned above course in 2017 - 2019. Questionnaires and testing methods were used to obtain empirical and experimental data. The results of teachers' training to use the integrated assessment technology revealed a positive dynamic in the development of all components of their diagnostic competence. They are generalized and given in Table 2 with the number of respondents (as a percentage) supporting them.

At the ascertaining stage of the experiment, the level of teachers' diagnostic competence development in the CG was $24.2 \%$, and it was $29 \%$, i.e. the basic level in the EG. At the end of the experiment this level rose by $43.7 \%$ (i.e. the basic level) in the CG, and by $70.4 \%$ (i.e. the professional and functional level) in the EG. Thus, the dynamic of positive changes in the levels of teachers' diagnostic competence was higher by $21.9 \%$ in the EG than in the CG.
Table 2. Dynamic of Foreign Language Teachers' Diagnostic Competence Development During the Pedagogical Experiment.

\begin{tabular}{|c|c|c|c|}
\hline $\begin{array}{c}\text { Teachers' } \\
\text { Diagnostic } \\
\text { Competence } \\
\text { Components }\end{array}$ & $\begin{array}{l}\text { Stage of the } \\
\text { Experiment }\end{array}$ & 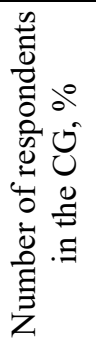 & 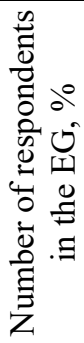 \\
\hline \multirow{3}{*}{$\begin{array}{l}\text { value- } \\
\text { motivational }\end{array}$} & ascertaining & 17,3 & 20,1 \\
\hline & forming & 30,3 & 57,2 \\
\hline & positive changes & 13,0 & 37,1 \\
\hline \multirow{3}{*}{ cognitive } & ascertaining & 38,1 & 42,9 \\
\hline & forming & 64,1 & 89,5 \\
\hline & positive changes & 26,0 & 46,6 \\
\hline \multirow{3}{*}{$\begin{array}{l}\text { operational- } \\
\text { activity }\end{array}$} & ascertaining & 21,7 & 27,8 \\
\hline & forming & 44,2 & 81,9 \\
\hline & positive changes & 22,5 & 54,1 \\
\hline \multirow{3}{*}{$\begin{array}{l}\text { reflexive- } \\
\text { corrective }\end{array}$} & ascertaining & 19,8 & 25,3 \\
\hline & forming & 36,2 & 52,9 \\
\hline & positive changes & 16,4 & 27,6 \\
\hline \multirow{3}{*}{ average } & ascertaining & 24,2 & 29,0 \\
\hline & forming & 43,7 & 70,4 \\
\hline & positive changes & 19,5 & 41,4 \\
\hline \multicolumn{2}{|c|}{$\begin{array}{l}\text { difference in changes between the CG } \\
\text { and the EG }\end{array}$} & \multicolumn{2}{|c|}{21,9} \\
\hline
\end{tabular}

The value-motivational $(57.2 \%)$ and reflexivecorrective (52.9\%) components of teachers' diagnostic competence appeared to be at the lowest level of their development, and the operationalactivity $(81.9 \%)$ and cognitive $(89.5 \%)$ components appeared to be at the highest level of their development. Such figures can be explained by the lack of teachers' awareness of the need for their development on the one hand, and by the pedagogical reality in the information society that forces the teachers to develop the cognitive and operational-activity components of their diagnostic competence on the other hand. In this connection, the military education system managers should pay more attention to teachers' advanced training in order to enrich their value-motivational sphere and to stimulate their "agent behavior" and "agency" of their pedagogical activity [21].

Generalizing the EG results $(\varphi *$ emp $=3,069, \varphi *$ emp $\left.>\varphi^{*} \operatorname{cr}(p \leq 0,01)>2,31\right)$ after the forming stage, we can claim with probability of $95 \%$ that the empirical distributions of teachers according to the levels of their diagnostic competence development are statistically significantly different from those results of the ascertaining stage. Therefore, checking the statistical plausibility of the forming stage results in the experimental group testifies to positive changes in the rise of the levels comprising teachers' diagnostic competence by all its components. 
Furthermore, it was revealed that the teacher, who has mastered the technology of integrated assessment, is able to consciously control the dynamics of their professional growth, use working time and make efforts more optimally during the diagnostic activities, save time due to ICT and specialized software applications, develop their diagnostic competence in particular and professional and pedagogical competence in general.

Generalizing the results of teachers' training in the application of the technology, we can point out the following achievements: deepening, systematization and concretization of theoretical knowledge on the usage of mathematical and statistical methods for processing students' tests outcomes; correct application of specialized software for calculating integral estimates, development of skills for using recent mathematical and statistical methods, ICT and specialized software, etc.

\section{Conclusion}

To sum it up, we can state that the elaborated technology of integrated assessment proved to solve at least two pedagogical problems: it contributes to the accuracy and reliability of the integral estimates of students' FLCC formation levels and it creates a methodological basis for the development of teachers' diagnostic competence.

In general, by introducing teachers' training on how to apply the technology, which involves the use of recent mathematical and statistical methods realized with the help of ICT, we achieved the following unique results:

- Firstly, it contributed into the development of teachers' diagnostic competence, in particular, its cognitive and operative-activity components; at the same time, the results revealed the lack of teachers' awareness and perception of the values within the information society;

- Secondly, it promoted the accuracy and reliability of the integral estimates of the students' FLCC formation levels;

- Thirdly, it provided adherence to the principles of impartiality in teachers' diagnostic activity due to the model-based simulation of the assessment process.

Together with this, our research does not solve all the problematic issues of foreign language teachers' diagnostic activity at the higher military education institutions, allowing enough room for further studies in this area. Some other issues require additional research on, for instance, how to improve the expert selection system for evaluating both the teachers' diagnostic competence development levels and the students' FLCC formation levels, how to increase the reliability of expert group opinion characteristics, how to expand the range of expert evaluation methods used in integrating these methods, how to determine the parameters of the artificial neural network model, how to expand the ability to process multiple-factor and multilevel statistical samples for artificial neural network learning process.

\section{References}

[1]. Baumert, J., Kunter, M. (2006). Ključna riječ: profesionalna kompetencija učitelja. Časopis za obrazovanje, 9(4), 469-520.

[2]. Aufschnaiter, C. V., Cappell, J., Dübbelde, G., Ennemoser, M., Mayer, J., Stiensmeier-Pelster, J., ... \& Wolgast, A. (2010). Establishing and Diagnosing Prospective Teachers' Diagnostic Competence. Poster presented at NARST, 1.

[3]. Klug, J. (2011). Modeling and training a new concept of teachers' diagnostic competence (Doctoral dissertation, Technische Universität).

[4]. Chernikova, O., Heitzmann, N., Fink, M., Timothy, V., Seidel, T. \& Fischer, F. (2019). Facilitating Diagnostic Competences in Higher Education - a Meta-Analysis in Medical and Teacher Education. Educational Psychology Review, 32, 157-196.

[5]. Edelenbos, P., \& Kubanek-German, A. (2004). Teacher assessment: The concept of 'diagnostic competence'. Language testing, 21(3), 259-283.

[6]. Ohle, A., \& McElvany, N. (2015). Teachers' diagnostic competences and their practical relevance. Special Issue Editorial. Journal for educational research online, 7(2), 5-10.

[7]. Wuttke, E., \& Seifried, J. (2013). Diagnostic competence of (prospective) teachers in vocational education: An analysis of error identification in accounting lessons. In From Diagnostics to Learning Success (pp. 225-240). Brill Sense.

[8]. Bruehwiler, C., Baer, M., Beck, E., Bischoff, S., Guldimann, T., Müller, P., \& Vogt, F. (2004, August). Adaptive Teaching Competency-A New Approach to Teacher Education. In First International Conference of EARLI SIG (Vol. 11, pp. 11-14).

[9]. Bruehwiler, C., \& Vogt, F. (2007, August). Adaptive teaching competency and student learning. In 12th Biennial Conference for Research on Learning and Instruction, Budapest, Hungary.

[10]. Niemierko, B. (2002). Ocenianie szkolne bez tajemnic. Wydawnictwa Szkolne i Pedagogiczne SA.

[11]. Trittel, M., Gerich, M., \& Schmitz, B. (2014). Training prospective teachers in educational diagnostics. In Teachers' professional development (pp. 63-78). SensePublishers, Rotterdam.

[12]. Klug, J., Gerich, M., \& Schmitz, B. (2016). Can teachers' diagnostic competence be fostered through training and the use of a diary?. Journal for educational research online, 8(3), 184-206.

[13]. Yahupov, V. V., \& Kyva, V. Y. (2019). Criteria and indicators of information and communication competence diagnostics development of teachers in the system of military education. Information Technologies and Learning Tools, 71(3), 248-266. 
[14]. Zastelo, O. (2018). Development of Diagnostic Competence of Foreign Language Teachers of the Higher Military Educational Establishments in Postgraduate Education. ( $\mathrm{PhD}$ thesis). National Defence University of Ukraine named after Ivan Cherniakhovskyi.

[15]. Novosad, V. P., \& Seliverstov, R. H. (2008). Metodolohiya ekspertnoho otsinyuvannya: konspekt lektsiy. K.: NADU. [in Ukrainian]

[16]. Gaidyshev, I. (2012). AtteStat Data Analysis Software. User's manual. Version 13. Piter Publishing House.

[17]. BaseGroup тм Labs. Deductor. Algorithm Guide. Version 5.2.0, 1995-2010.
[18]. Barth, C., \& Henninger, M. (2012). Fostering the Diagnostic Competence of Teachers with Multimedia Training-A Promising Approach?. Interactive multimedia, 49-66.

[19]. STADIA statistical software, http://statsoft.msu.ru/Podr2 1.htm

[20]. Zastelo, O., Butvin, B. (2016). Methodical Recommendations for Teachers on the Application of the Integrated Assessment Technology.

[21]. Yagupov, V. (2013). Teacher and Student as Agents of Learning in the Ivan Zjazun's Philosophic and Pedagogical Conception. In book Ivan Zjazun's Pedagogical Masterhood, 334-339. 